\title{
Emancipação das mulheres no discurso feminista online: dimensões textuais de uma luta hegemônica
}

\author{
Danillo da Conceição Pereira Silva ${ }^{1}$ \\ Programa de Pós-Graduação em Letras, Universidade Federal de Sergipe, São Cristóvão, Sergipe, Brasil \\ Departamento de Formação Geral, Instituto Federal de Alagoas, Santana do Ipanema, Alagoas, Brasil
}

\begin{abstract}
Resumo: Este artigo tem como objetivo refletir acerca da produção textual-discursiva de sentidos emancipatórios para as mulheres em dois textos postados pela fanpage do coletivo feminista Não Me Kahlo, no Facebook, por ocasião do Dia Internacional da Mulher, em 2017. Para esta análise, calcada numa visão discursiva e crítica dos processos de referenciação que atuam na (re)construção de objetos de discurso que (re)categorizam as mulheres no discurso feminista online, apostamos na articulação teórico-metodológica entre perspectivas advindas da Linguística de Texto contemporânea e da Teoria Social do Discurso. As análises realizadas apontam, por um lado, o potencial político das práticas textuais-discursivas em contextos de ativismo digital, no que tange à produção de sentidos contra-hegemônicos para as mulheres, a exemplo da liberdade sexual e da transexualidade, e por outro, para a produtividade da interface teórica proposta, no que concerne a articulação entre elementos do plano textual e discursivo.
\end{abstract}

Palavras-chave: Referenciação; Teoria Social do Discurso; Discurso Feminista; Luta Hegemônica.

Title: The Women's Emancipation on Feminist Online Speeches: textual dimensions of a hegemonic struggle

Abstract: This article aims to reflect about the textual-discoursive production of emancipatory senses related to the women in two texts posted on the Facebook page of the feminist group Não Me Kahlo, by reason of International Women's Day, in 2017. This analysis was based on a discursive and critical vision of the referencing processes which operate in the (re)construction of the subjects of the speeches and that (re)categorize the women in the online feminist speeches, we can bet on the theoretical-methodological articulation between some perspectives from the contemporary Textual Linguistic and the Social Theory of Discourse. This analysis was done in cyber-activists contexts concerning to the production of counter-hegemonic senses to the women, as for example of the sexual freedom and of the transsexuality, in addition to the productivity of theoretical interface proposed in what concerns about the articulation between elements of the textual and discursive plane.

Keywords: Referencing process; Social Theory of Discourse; Feminist Speech; Hegemonic-struggle.

\footnotetext{
${ }^{1}$ Doutorando e Mestre em Letras/Linguística Aplicada pelo Programa de Pós-Graduação em Letras da Universidade Federal de Sergipe (PPGL/UFS). Professor de Língua Portuguesa do Instituto Federal de Educação, Ciência e Tecnologia de Alagoas (IFAL). ORCID: http://orcid.org/0000-0002-5879-5999 E-mail: danillosh@gmail.com
} 


\section{Situando a discussão}

Os estudos da linguagem, embora fortemente influenciados por ideologias modernistas de ciência, calcadas numa visão cartesiana e positivista da produção do conhecimento, têm se aberto gradativamente à revisão de seus modos de fazer pesquisa, especialmente graças à complexificação que as vertiginosas descontinuidades e rupturas da vida no presente produzem sobre o modo como concebemos a linguagem. Dentre essas revisões em curso estão aquelas que fazem, hoje, parecer truísmo afirmar que esta seja uma instância multissemiótica eminentemente complexa, dialeticamente articulada às estruturas sociais, imbuída de fricções ideológicas, implicada nas disputas sociais, nos modos de agência política de diferentes grupos e em suas performances identitárias.

Nesse sentido, questões de linguagem estão amplamente imbricadas em práticas sociais como as do ativismo feminista realizado em ambientes digitais. Nesses espaços, os discursos reverberados em diversos textos, de caráter altamente multimodal, tornam-se as principais estratégias enunciativo-simbólicas na luta contra a naturalização de significados sociais violentos produzidos para/sobre as mulheres. Tendo isso em vista, sustentamos que o processamento referencial que produz objetos de discurso com vistas a (re)categorizar as mulheres nos textos ativistas torna-se importante elemento para a compreensão das lutas hegemônicas em torno da elaboração dos significados sociais em jogo, configurando-se, desse modo, índice semiótico de uma ação política feminista na linguagem.

Assim, como o objetivo de evidenciar a produção de sentidos emancipatórios e contrahegemônicos para/sobre as mulheres ${ }^{2}$ em contextos de ativismo digital, propomos uma análise textual-discursiva crítica ${ }^{3}$ dos processos de referenciação em funcionamento em duas postagens realizadas pela fanpage do coletivo feminista brasileiro Não Me Kahlo, na rede social Facebook, por ocasião do Dia Internacional da Mulher, em 8 de março de 2017. A fim de encaminhar tais análises, apostamos na articulação estratégica entre premissas dos

\footnotetext{
${ }^{2}$ Neste trabalho, partimos de uma concepção não essencialista de gênero social, a qual encara as diversas possibilidades de identificação existentes como frutos de processos de estilização, repetições citacionais, performativamente produzidos a partir de uma série de atos discursivos e corporais, situados socioculturalmente, conforme pensado por Butler (1997; 2017). Nesse sentido, ao usarmos o termo "mulheres/mulher" não estamos nos referindo a pessoas dotadas de um feixe de caracteres consagrados na narrativa médico-científica como definidores desse padrão de gênero, mas a todas as pessoas que vivenciam uma experiência de gênero a partir da qual se sentem identificadas com tal categoria, de modo genérico, mediante todos os deslocamentos e alargamentos os quais ela possa comportar.

${ }^{3} \mathrm{O}$ que aqui enunciamos como uma perspectiva crítica, em estudos da linguagem, diz respeito a "empreendimentos teóricos (...) cujo o horizonte seja a insistência em alguma forma de emancipação" em função de uma "pluralidade de demandas e de um conjunto de tensões (como é o caso daquelas em torno das disputas sociais e políticas para representar a mulher no discurso) não imaginado pela modernidade filosófica e seu projeto de ciência", as quais se levantam como uma alternativa ante "o esgotamento dos modelos de análise que floresceram sob a égide do lluminismo e, sob a influência avassaladora do positivismo" (FERREIRA; RAJAGOPALAN, 2016, p. 19-20, editado).
} 
estudos da referenciação na Linguística de Texto contemporânea e da Análise Crítica do Discurso (ou Análise de Discurso Crítica), mais especificamente daqueles desdobramentos teórico-metodológicos da Teoria Social do Discurso (FAIRCLOUGH, 1997, [2001] 2003) relativos às noções de discurso, luta hegemônica, mudança discursiva e social.

Tendo sido realizada uma contextualização mais geral das discussões propostas neste artigo, a seguir, na primeira seção, apresentamos o coletivo feminista Não Me Khalo e sua fanpage de ativismo digital no Facebook, prática social na qual os textos analisados estão inseridos. Em seguida, na segunda seção, discutimos o fenômeno da referenciação, enfatizando os processos de categorização e recategorização, à luz de uma perspectiva efetivamente discursiva e crítica. Por fim, na quarta e última seção, mediante a análise dos processos de referenciação à luz da articulação teórica proposta, discutimos a produção textual-discursiva de sentidos emancipatórios em torno das mulheres como forma agência política na linguagem, engajada na luta hegemônica por condições de representação que desafiem normas de gênero social patriarcais, sexistas e misóginas, a exemplo da liberdade sexual e da liberdade de autodeterminação de gênero.

\section{Ativismo digital e a fanpage do coletivo feminista Não Me Kahlo no Facebook}

Dentre as inúmeras transformações que o advento e a evolução da internet proporcionaram à vida na modernidade tardia ${ }^{4}$ (GIDDENS, 1991, 2002), estão a dinamização e a potencialização das forças de intervenção dos movimentos sociais na vida civil. Mediante a possibilidade de disponibilizar, para além das fronteiras cronotrópicas, conteúdos, informações, dados, mensagens e, acima de tudo, conectar digitalmente sujeitos sociais em torno de causas defendidas, o ciberespaço tornou-se, conforme discute Moita Lopes (2010), uma arena de conscientização, luta social e intervenção política. Nesse sentido, "com a migração para a Web, as entidades aderem à comunicação em tempo real, sem centros fixos de enunciação" (MORAES, 2001, p. 3), arregimentando, a cada postagem, "novos usuários, os quais se convertem, potencialmente, em produtores e emissores de informações, em condições de serem consumidas a todo instante" (MORAES, 2001, p. 3).

Como parte de tal realidade, surge em 2015, no Brasil, a fanpage do coletivo feminista Não Me Khalo, o qual assim se apresenta:

\footnotetext{
${ }^{4}$ Conforme discutem Resende e Ramalho (2016, p. 30), para o sociólogo Antony Giddens, "a modernidade tardia corresponde a presente fase de desenvolvimento das instituições modernas, marcada pela radicalização dos traços básicos da modernidade: separação de tempo e espaço, mecanismos de desencaixe e reflexividade institucional. Em vários aspectos, as instituições modernas apresentam certas descontinuidades em relação a culturas e modos de vida pré-modernos em decorrência de seu dinamismo, do grau de interferência nos hábitos e costumes tradicionais e de seu impacto global."
} 
O Coletivo Feminista Não Me Kahlo nasceu como um espaço de estudo e debate sobre o feminismo em suas diversas vertentes, respeitando a pluralidade social, a individualidade e valorizando o trabalho em conjunto para a construção de uma sociedade igualitária, dando atenção às demandas e pautas feministas. A fanpage é mais mídia criada com o intuito de levar conhecimento e ampliar o debate para a desconstrução do machismo na sociedade. Com o passar do tempo, percebemos a necessidade de ampliar nosso trabalho. $E$, assim, surgiu a ideia de fundação de uma associação civil (uma organização não-governamental) que virá em breve! (NÃO ME KHALO, $s / d, s / p$.$) .$

Na figura 1, a seguir, é apresentada a página inicial da fanpage do coletivo feminista Não Me Kahlo no Facebook, atualizada em 18 de agosto de 2018.

Figura 1 - Página inicial da fanpage do Não Me Khalo no Facebook

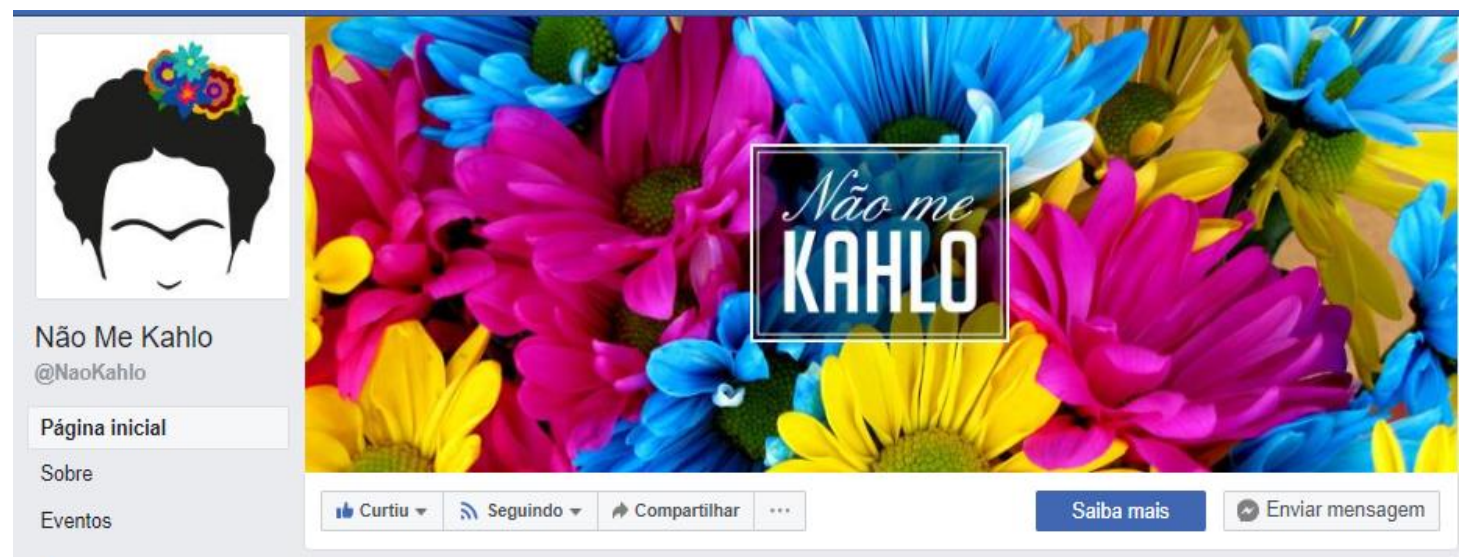

Fonte: Disponível em: <http://www.facebook.com/naomekahlo>. Acesso em: 18 ago. 2018

Podendo ser considerada uma fanpage de sucesso, haja vista a marca de 1.236.864 curtidores e de 1.232.217 seguidores, a página está, além do Facebook, presente em outras redes sociais como Twitter, Instagram (45,6k seguidores), Tumblr e Youtube (2.886 inscritos e o vídeo mais acessado com 60.661 visualizações), além de possuir um blog ${ }^{5}$ homônimo, no qual são postados materiais autorais, bem como replicados de outros sítios da internet.

Nessa direção, podemos compreender como "a organização em redes, dentro e fora da Internet, revela-se inovadora. Elas facilitam a intercomunicação de indivíduos e agrupamentos heterogêneos que compartilham visões de mundo, sentimentos e desejos" (MORAES, 2001, p. 2-3). Nesse sentido, tais articulações, própria dos ativismos digitais, como o desenvolvido pela fanpage em discussão, "servem de estuários para a defesa de identidades culturais, a promoção de valores éticos e a democratização da esfera pública (MORAES, 2001, p. 2-3). Assim, "a rede [a rede social digital engajada em movimentos] se torna um conceito propositivo, a partir não mais da hierarquização do poder entre os participantes, e sim de

\footnotetext{
${ }^{5}$ Disponível em: http://www.naomekahlo.com/. Acesso em: 18 ago. 2018.
} 
relações mais horizontalizadas, abertas ao pluralismo político-cultural" (MORAES, 2001, p. 23).

Vale salientar que esse espaço está sendo ocupado, seguido e compartilhado por um público não exclusivamente formado por mulheres e não engajado apenas no debate de questões relativas às pautas do movimento feminista, mas, envolve, também, outros sujeitos que, no referido contexto virtual, se engajam e se articulam na luta por justiça social para diferentes grupos minoritários. Na fanpage, é possível encontrar também discussões relativas ao empoderamento de pessoas negras, travestis/transexuais, lésbicas, bissexuais, homossexuais, indígenas, periféricas, dentre outras. Graças a considerável adesão dos usuários-cidadãos, nas mais diversas plataformas e redes da internet, tendo em vista o significativo número de seguidores e a propagação dentro e fora do movimento feminista, foi lançada uma proposta de fundação de uma organização não-governamental que, até a conclusão desta pesquisa, não havia se solidificado, conforme informações do blog Não Me Khalo.

Diante do panorama apresentado, nota-se que, mediante as transformações digitais operadas com o advento da Web $2.0^{6}$, e a possibilidade de surgimento de redes sociais como - Facebook, surgiram outras formas de interação, debate e reflexão, uma vez que o ciberespaço atribui voz e possibilidade de participação mais ampla na vida social, por meio dos recursos específicos desses espaços, a um número gigantesco de pessoas que interagem e colaboram entre si na construção de um conhecimento compartilhado no/sobre o mundo, na construção compartilhada do mundo. Nesse sentido, como discute Braga (2015), apesar de o acesso a esses recursos digitais de comunicação não ser uma garantia absoluta de transformação dos problemas que neles encontram espaço de discussão, "é importante entendermos de que forma as tecnologias digitais da informação e da comunicação podem efetivamente contribuir para uma participação popular efetiva e, portanto, mais efetivamente democrática" (BRAGA, 2015, p. 20).

Desse modo, de acordo com Santaella (2010) e Coelho (2012), as mídias digitais são suportes indispensáveis para a difusão dos debates e para o estabelecimento de interações sociais como as compreendemos na contemporaneidade. Graças à horizontalização das práticas de interação, bem como ao menor grau de interdição de pautas e de narrativas sociais visibilizadas, em se comparando ao que ocorre nas mídias hegemônicas, características próprias desses espaços, muitos movimentos sociais também ganharam força e visibilidade

\footnotetext{
${ }^{6}$ As diferenças mais significativas entre a Web 2.0 e sua versão anterior, a Web 1.0, consistem nas possibilidades de dinâmica e de interatividade. Se na primeira os recursos tecnológicos criaram espaços infinitos para o armazenamento e a circulação de dados via interconexão entre diferentes páginas, produzindo, com isso, uma rede de informações, a segunda versão agregou a essas possibilidades o aspecto interativo, fazendo o internauta passar de consumidor passivo de conteúdos para colaborador, seja através da possibilidade expressar sua opinião acerca do que estava disponível na Web, através de um comentário, por exemplo, seja criando seus próprios conteúdos. Com a versão 2.0 surgiram as possibilidades de interconexão entre usuários/as, as redes sociais digitais, os blogs, os sites de informação colaborativa, dentre outros.
} 
com a propagação de sua militância na internet e em diversas plataformas digitais. Sem sombra de dúvida, o feminismo é um potente exemplo disso, chegando ao ponto de, como discutem autoras como Lemos (2009), podermos falar em um Ciberfeminismo como fenômeno específico dentro da chamada terceira onda do movimento feminista, o qual está, dentre outras coisas, engajado em "utilizar as tecnologias de rede para a modificação da realidade político-social das mulheres" (HARAWAY, 2009, p. 47).

Decorrente dessas relações, o ativismo digital tem sido potencializado, experimentando "os esforços de intervenção dos movimentos sociais no cenário político, graças à singularidade que lhe permite divulgar, em qualquer espaço-tempo, diversas atividades e expressões da vida, sem submetê-las a hierarquias de juízos" (MORAES, 2005, p. 70, tradução nossa). Assim, o ciberespaço tem se convertido num lugar de luta política, de denúncia de abusos de poder e violências, desigualdades e opressões, utilizando a democratização própria desse fenômeno sociocomunicativo como aliado da militância social em favor de grupos marginalizados, como é o caso da página Não me Khalo. Vale ressaltar que, a revelia dessas possibilidades de participação social ampliadas pelas práticas de ativismo digital, nosso foco de reflexão aqui, esses mesmos espaços têm se tornado potentes em disseminar discursos de ódio e práticas de violência linguística, baseadas em raça, gênero e sexualidade, dentre outros marcadores da diferença, contra grupos sociais vulnerabilizados, conforme discutimos em Silva (2017).

Nesses espaços, os discursos reverberados em diversos textos, de caráter altamente multimodal, passaram a ser as principais estratégias enunciativo-simbólicas na luta hegemônica, com vistas ao combate à naturalização de significados sociais violentos produzidos para/sobre as mulheres. No interior de tais práticas sociais situadas, 0 processamento referencial que produz objetos de discurso com vistas a (re)categorizar as mulheres no discurso torna-se importante elemento para a compreensão das disputas semióticas em torno da elaboração de significados sociais em jogo, participando assim de uma ação política na linguagem que visa produzir significados emancipatórios e contrahegemônicos para tais sujeitos.

Após as considerações aqui realizadas, nas próximas seções, apresentamos discussões teóricas que visam a evidenciar o modo pelo qual processos de referenciação, quando tomados em perspectiva crítica, podem constituir-se instrumentos da luta contra-hegemônica das mulheres, com vistas a sua emancipação, por meio da confrontação de vozes sociais ligadas ao machismo e à subalternização da condição das mulheres e de suas possibilidades identitárias mediante a recategorização de objetos de discurso. 


\section{Referenciação e (re)categorização: dimensões textuais de uma luta hegemônica}

Segundo perspectivas filosóficas, e linguísticas ${ }^{7}$, que assumem o mundo como realidade autônoma, pressupõe-se que os "objetos" possuem significados estáveis e préestabelecidos, inscritos, de algum modo, em sua própria natureza ou estrutura linguística. De tais posições essencialistas advêm noções segundo as quais os sentidos para o mundo e, consequentemente, para as formas linguísticas, estão disponíveis de modo autônomo e pacífico na própria realidade empírica, mediante ligação unívoca entre "objeto" e significado. Dessa perspectiva, o uso da linguagem constitui-se num processo de reflexão especular da realidade, um processo de referência.

A posição acima caracterizada, ainda presente em maior ou menor grau em determinadas orientações dos estudos da linguagem, vem sendo refutada por diferentes abordagens, as quais assumem uma perspectiva pragmática sobre a produção de sentidos, consequentemente consagrando o uso, em situações multifatoriais de interação concreta, como o momento particular da construção perene de significados. Nesse viés, abordagens como a Teoria da Referenciação, em suas diferentes apropriações, assumem a realidade social como um produto de "nossas práticas discursivas e cognitivas social e culturalmente situadas, em versões públicas do mundo" (MONDADA; DUBOIS, 2003, p. 17).

Nesse sentido, o pressuposto da referenciação como atividade discursiva (MARCUSCHI, 1998) de construção do mundo, dos sujeitos e de suas significações no próprio discurso, implica, desse modo, uma visão não-referencial da língua e da linguagem. Assim, referenciação não diz respeito à representação especular de coisas ou estados de coisas no discurso, mas corresponde especialmente àquela relação estabelecida entre o texto, enquanto entidade semiótica complexa, e as instâncias não-semióticas nas quais ele é produzido e interpretado. No bojo desse processo, mediante os processos de referenciação, realiza-se a construção de objetos de discurso na "intersubjetividade das negociações, das modificações, das ratificações de concepções individuais e públicas do mundo" (MONDADA; DUBOIS, 2003, p. 20).

Dessarte, os objetos de discurso não se confundem com a realidade comumente nomeada como "extralinguística", a qual só nos é acessível pelo discurso, mas têm seus significados (re) construídos nas relações dialéticas estabelecidas nos processos de interação. Desse modo, radicalizando essa concepção, podemos afirmar que as condições materiais e simbólicas de existência dos sujeitos são realidades produzidas, mantidas e/ou alteradas,

\footnotetext{
${ }^{7}$ Segundo discute Salomão (2005), a concepção de que a referência guardaria uma relação especular com seu referente, presente em campos como a semântica linguística, é ressonância de perspectivas advindas da filosofia analítica, as quais, segundo nosso ver, posicionam-se em um polo diametralmente oposto àquela concepção de linguagem que funda o marco teórico de abordagens de natureza pragmática e interacionista, como a que é sustentada neste artigo.
} 
inclusive, por constantes processos de referenciação em funcionamento na elaboração de objetos de discurso e em suas dinâmicas de categorização e recategorização. Dessa visada,

\begin{abstract}
um objeto de discurso caracteriza-se pelo fato de construir progressivamente uma configuração, enriquecendo-se com novos aspectos e propriedades, suprimindo aspectos anteriores ou ignorando outros possíveis, que ele pode associar com outros objetos ao integrar-se em novas configurações, bem como de articular-se em partes suscetíveis de autonomizarem por sua vez em novos objetos. O objeto se completa discursivamente (MONDADA, 1994, p. 64 apud KOCH, 2004, p. 79).
\end{abstract}

Tendo em vista tais processos, nos parece irrefutável afirmar que uma língua não existe sem os sujeitos histórica, social e politicamente situados que a utilizam, muito menos sem os eventos discursivos nos quais eles intervêm e nos quais mobilizam suas percepções, construídas também de modo contingente. Esses sujeitos, então, "constroem mundos textuais cujos objetos não espelham fielmente o "mundo real", mas são, interativamente e discursivamente, construídos, em meio às práticas sociais, ou seja, são objetos-de-discurso" (LIMA, 2007, p. 141).

Dessa maneira, fica evidente que tais objetos não são estáticos, mas se reelaboram dentro de diversos contextos interacionais, de modo que, no momento em que se passa da língua ao discurso, torna-se indispensável recorrer a conhecimentos socialmente compartilhados a partir dos quais as práticas discursivas são estabelecidas, mobilizando, assim, elementos do contexto local da interação em articulação com contextos mais globais.

Diante da natureza instável da língua e da linguagem, a fim de que significados possam ser compartilhados socioculturalmente e, por isso, inteligíveis, há que se pensar em processos de estabilização que operam nesse sentido. Tais mecanismos agem com vistas a discretizar a instabilidade constitutiva de todo código semiótico, produzindo, com vistas a esse fim, efeitos de evidência e estabilidade para os significados construídos, sejam eles atribuídos a meros objetos ou a determinadas parcelas da população, tais como grupos sociais minoritários.

Dentre os referidos processos de estabilização e discretização estão os processos de categorização. Cotidianamente, lançamos mão de categorias para descrever e classificar o mundo, porém essas mesmas categorias mudam, sincrônica e diacronicamente, seja em discursos do dia a dia ou científicos, elas são múltiplas e inconstantes, logo os objetos de discurso que estão inseridos nessas categorias também são passíveis de atualização, de (re) construção, uma vez que "estes não preexistem 'naturalmente' à atividade cognitiva e interativa dos sujeitos falantes, mas devem ser concebidos como produtos fundamentalmente culturais - desta atividade" (APOTHÉLOZ; REICHLERBEGUÉLIN, 1995 apud $\mathrm{KOCH}, 2005$, p. 33).

Nessa direção, em tal abordagem dinâmica, a qual visa questionar os processos de estabilização e discretização de categorias, implica uma visão que leva em conta não somente a atividade de sujeitos empíricos na produção de sentidos, mas a ação de sujeitos 
sociocognitivos, "mediante uma relação indireta entre os discursos e o mundo. Esse[s] sujeito[s] constrói[em] o mundo ao curso do cumprimento de suas atividades sociais e o torna estável graças às categorias (...) manifestadas no discurso" (MONDADA; DUBOIS, 2003, p. 20).

É nesse sentido que "os objetos de discurso, enquanto entidades construídas ao longo da interação discursiva, podem sofrer modificações - isso é o que se entende por recategorização referencial" (SILVA; CUSTÓDIO FILHO, 2013, p. 61). Tal como, conforme discute Koch (2003, p. 83-84), "durante o processo de compreensão desdobra-se uma unidade de representação extremamente complexa, pelo acréscimo sucessivo e intermitente de novas informações e/ou avaliações explícitas acerca do referente".

Mediante essas ideias, intentando refletir sobre tais dinâmicas da luta hegemônica no discurso feminista online, em postagens da página Não Me Kahlo, como discutido na seção anterior, torna-se indispensável ponderar de que modo (em termos formais e de conteúdo, composicionais e estilísticos) os textos têm se reconfigurado no interior das práticas sociais em rede, levando em conta que:

À integração das diferenças, à convivência com conteúdos midiáticos produzidos para compor o universo simbólico das massas, à transnacionalização de culturas, somam-se agora, como nunca, as tecnologias. As estruturas (físicas e ideológicas) a partir das quais surge o pensamento sociológico moderno dão lugar (ou convivem com), nesse início de século 21 , a outra esfera - a da informação - na qual se efetivam todas as ações representativas dos sistemas econômico, social e político do mundo físico, e do universo cibernético, mediático e simbólico. [...] Todas as práticas e significados do mundo de hoje acontecem inevitavelmente pelo, entre, ou por causa do universo digital. A esse fenômeno denomina-se cibercultura. Esta condição se caracteriza pela produção e usos de conteúdos através dos mass media e por tudo que compõe o processo de interação nas redes digitais (web, Twitter, Facebook podcasts, GPS, telefonia celular etc.). Neste cenário ressurgem especulações sobre o papel da comunicação e da informação, graças ao imenso número de habitantes do planeta que possui instrumentos neotecnológicos (GODOI, 2009, p. 76).

Conforme discutido até aqui, compreender como, no ciberespaço, "dinâmicas de funcionamento discursivo, produção de sentidos e efeitos de identidade/alteridade constituem-se atravessamentos pragmáticos importantes" (SILVA, 2017, p. 81) na produção dos discursos em redes digitais, torna-se um elemento considerável na análise de textos produzidos no ciberespaço. Tendo em vista sua natureza de forte apelo sensorial, o processamento multissemiótico ${ }^{8}$ de textos e gêneros nas esferas de circulação online é

\footnotetext{
8 "Multissemiótico é um termo que designa a junção de várias semioses (várias linguagens). Para nos comunicarmos precisamos criar convenções de sentidos a determinadas formas de expressão. É assim que se criam as diferentes linguagens. Cada linguagem possui uma linguagem oral, formas de registro específicos para a linguagem escrita, diferentes convenções para interpretar imagem, cor e assim por diante. Por exemplo, o luto é representado pela cor preta no Ocidente e pela cor branca no Japão" (BRAGA, 2013, p. 139).
} 
marcado pelo emprego de uma abundante gama de recursos imagéticos (como também sonoros), os quais, por um lado, integram de modo constitutivo a produção de sentidos em textos digitais e, por outro, escapam às teorizações e descrições clássicas em torno do processamento textual-discursivo centradas na "tese da dominância verbal" (DELPHINO, 2001, p. 2), a qual têm sido paulatinamente abalada.

Diante desse impasse, não seria forçoso pensar que "o projeto de multimodalidade prevê que os produtores do texto estão fazendo uso deliberado de tipos de modos representacionais e comunicacionais que co-ocorrem dentro de um texto" (DELPHINO, 2001, p. 2). Nesse sentido, como discutido por Custódio Filho (2009, p. 2931), as reflexões sobre a multimodalidade podem ainda ser expandidas para além de seu caráter de "recurso" disponível na constituição de textos e gêneros, dando-se vez a pensar "outros aspectos que fazem parte da interação pela linguagem, como, por exemplo, as práticas referenciais que compõem os gêneros e textos" (CUSTÓDIO FILHO, 2009, p. 2930-2931). Assumindo tal perspectiva, e, tendo em vista as discussões fulcrais para este trabalho, ficam salientes as observações no que tange à "participação dos aspectos multimodais na construção dos objetos-de-discurso" (CUSTÓDIO FILHO, 2009, p. 2930-2931).

No que tange à referida instância multimodal implicada nos processos de referenciação, em semelhança ao que ocorre com a participação de signos de natureza propriamente verbal, há que se levar em conta também o modo como os sujeitos sociais se reconfiguram diariamente por meio desses elementos; a forma como se mostram virtualmente, como se posicionam através do que compartilham, ou não, as páginas as quais curtem, os perfis que seguem, os conteúdos aos quais a rede de amigos estabelecida faz emergir no seu feed; todos esses aspectos ganham relevância, uma vez que tornam-se material simbólico disponível, em diferentes semioses, para a criação de uma imagem virtual ou, utilizando uma linguagem da rede, para a criação do seu próprio "avatar" ${ }^{9}$, mediante as complexas tramas de sociabilidade estabelecidas.

Dessa perspectiva, numa visão crítica no que tange à produção de sentidos sobre as mulheres no discurso, podemos entrever como os processos de (re) categorização, enquanto mecanismos que visam a estabilizar sentidos socialmente compartilhados, veiculam construtos ideológicos ${ }^{10}$ que podem agir no sentido de questionar visões hegemônicas sobre as mulheres, categorizadas historicamente como subalternas, seja do ponto de vista moral,

\footnotetext{
${ }^{9}$ Originalmente relacionado a uma figura religiosa do Sânscrito, em contextos de jogos digitais, o termo "avatar" designa um corpo virtual assumido pelos jogadores/pelas jogadoras, o qual é capaz de assumir diferentes identidades construídas mediante uma série de tarefas de caracterização, a depender da modalidade de jogo em questão.

10 Tendo em vista a polissemia do termo, sinalizamos que, neste trabalho, em coerência com os princípios ontológicos da Teoria Social do Discurso, "ideologia" diz respeito às "significações/construções da realidade (o mundo físico, as relações sociais, as identidades sociais) que são construídas em várias dimensões das formas/sentidos das práticas discursivas e que contribuem para a produção, a reprodução ou a transformação das relações de dominação" (FAIRCLOUGH, 2003, p. 117).
} 
intelectual ou econômico, dentre outros sentidos que precarizam sua condição sociopolítica desde uma instância semiótica, segundo diferentes ordens do discurso (familiares e religiosas, por exemplo).

Nesse contexto, o tensionamento da aparente estabilidade desses sentidos pode contribuir para a desnaturalização de construtos sociocognitivo-discursivos misóginos hegemônicos em nossa sociedade, evidenciando que os fenômenos de referenciação, como a categorização e a recategorização, ainda que se processem mediante a mobilização de recursos de natureza lexical ou imagética, na superfície textual, respondem, em grande medida, a instâncias discursivas, da ordem do político, do social e do cultural, implicadas na sua elaboração. Essa possibilidade diz respeito ao fato de que "são os indivíduos, inseridos em práticas discursivas e sociais, que corroboram para a manutenção ou transformação de estruturas sociais - uma visão dialética da relação entre estrutura e ação" (RESENDE, 2016, p. 45-46).

Tendo em vista tais posições, sustentamos que a construção de redes de referências no interior dos textos, mediante a construção e reconstrução de objetos de discurso, em função da relação dialética entre discurso e sociedade, participa da luta hegemônica a qual consiste "na disputa pela sustentação de um status universal para determinadas representações particulares - do mundo material, mental e social" (RESENDE, 2016, p. 46). É graças a essa dinâmica de funcionamento que os processos de categorização e recategorização respondem a constrangimentos ideológicos implicados "no estabelecimento e na manutenção de relações de dominação" (RESENDE, 2009, p. 16), uma vez que textos inseridos em eventos sociais possuem potencial causal, produzindo mudanças/reforços em nossos conhecimentos, crenças, valores e afins (FAIRCLOUGH, 2003).

Assumindo tal visada, com Faircolugh (1997, p. 80), no que tange às relações estabelecidas entre discurso e hegemonia, pensamos que:

A prática hegemônica e a luta hegemônica assumem, em grande medida, a forma de prática discursiva na interação oral ou escrita. O conceito de hegemonia implica o desenvolvimento - em vários domínios da sociedade civil (...) - de práticas que naturalizam as relações entre ideologias específicas e que são, na maioria, práticas discursivas (FAIRCLOUGH, 1997, p. 80).

Em face do exposto, consideramos que "convenções discursivas naturalizadas" por meio de processos textuais-discursivos, a exemplo da construção de objetos de discurso nos quais as mulheres são significadas em categorias nas quais sua dignidade e autonomia lhes são negadas, configuram-se um "mecanismo extremamente eficaz para perpetuar e reproduzir dimensões culturais e ideológicas da hegemonia" (FAIRCLOUGH, 1997, p. 80). Dessa visada, podemos pensar ainda que "um objetivo importante na luta hegemônica é a desnaturalização de convenções existentes e a sua substituição por outras" (FAIRCLOUGH, 1997, p. 80). Isto é, a desconstrução de contextos de uso os quais reiteram a negociação de 
objetos de discurso perniciosos no que diz respeito às condições de pluralidade e equidade de gênero na sociedade.

É pensando que os eventos discursivos não são estanques, mas estabelecem relações de cumulação sobre as disputas sociais e lutas ao seu redor, e que eles podem estar orientados à preservação e à reprodução das relações e das hegemonias tradicionais de gênero, ou podem ser "uma contribuição para a transformação dessas relações mediante a luta hegemônica" (FAIRCLOUGH, [2001], 2016, p. 133), que podemos pensar nas relações entre mudança social e mudança discursiva e sua dimensão textual, uma vez que:

a mudança (social) deixa traços nos textos na forma de coocorrência de elementos contraditórios ou inconsistentes - mesclas de estilos formais e informais, vocabulários técnicos e não-técnicos, marcadores de autoridade e familiaridade (...). À medida que uma tendência particular de mudança discursiva se estabelece e se torna solidificada em uma nova convenção emergente, o que é percebido pelos intérpretes, num primeiro momento, como textos estilisticamente contraditórios perde o efeito de "colcha de retalhos", passando a ser considerado "inteiro". (FAIRCLOUGH, [2001], 2016, p. 133).

Tendo em vista as articulações teóricas apresentadas, apesar de Linguística de Texto e Análise Crítica do Discurso assumirem diferentes objetos de pesquisa e diferentes ênfases teórico-metodológicas que, numa visão organizativa clássica dos estudos linguísticos os situariam em diferentes níveis de análise linguística, não seria forçoso afirmar que para ambos os campos, os textos ${ }^{11}$, em seus diferentes gêneros, são espaços potenciais de (re) construção de significados sociodiscursivos para sujeitos e entidades, sejam eles reais ou imaginários, classificando-os de modos específicos, atribuindo-lhes determinadas funções, propriedades, características, as quais se realizam em diferentes processos textuais-discursivos, como é o caso daqueles da ordem da referenciação para os quais nos voltamos aqui.

Usando as lentes dessa articulação teórica, na próxima seção, ao propormos analisar o modo como sentidos emancipatórios têm sido produzidos em torno das mulheres, tomamos os textos e seus processos de constituição em face de seus contextos sociais mais amplos, em uma análise que visa a ultrapassar uma visão estrutural do texto ou restrita à descrição dos mecanismos de funcionamento do fenômeno estudado. Graças a tal intenção, com vistas a relacioná-lo aos construtos sociais e culturais nos quais foram produzidos, objetivamos praticar uma análise de textos nas práticas sociais as quais integram.

\footnotetext{
${ }^{11}$ Sobre a categoria "texto", vale ressaltar que, "na vida contemporânea, em que os escritos se misturam com imagens estáticas (fotos, ilustrações) e em movimento (vídeos) e com sons (sonoplastias, músicas), a palavra 'texto' se estendeu a esses enunciados híbridos de 'novo' tipo, de tal modo que falamos em 'textos orais' e 'textos multimodais', como as notícias televisivas e os vídeos de fãs do YouTube" (ROJO; BARBOSA, 2015, p. 25).
} 


\section{Liberdade sexual e transexualidade: a produção textual-discursiva de sentidos emancipatórios para as mulheres no discurso feminista online}

Considerando as articulações teóricas desenvolvidas ao longo desta discussão, na presente seção, analisamos o modo como as mulheres, enquanto sujeitos sociais, têm sido construídas no discurso feminista online, a partir da observação das estratégias de processamento textual concernentes à referenciação e à categorização engajadas na construção de objetos-de-discurso. Desse ponto de vista, compreendemos que "a linguagem é usada para manter ou desafiar [as relações de poder e ideologia] no mundo contemporâneo" (MELO, 2011, p. 68). Em razão disso, nosso objetivo consiste em "investigar esses traços e pistas na intenção de tornar visíveis as relações entre a linguagem e outras práticas sociais, que são dadas como naturais" (MELO, 2012, p. 68).

Os textos analisados, embora não tenham sido postados originalmente pela página em discussão - e sim pela fanpage da Prefeitura de Fortaleza, Ceará, Brasil ${ }^{12}$ - uma vez compartilhadas por ela, passam a compor o espectro de ação discursiva e social realizada pelo coletivo feminista na rede, o que pode ser entendido a partir do complexo fenômeno da autoria colaborativa em espaços digitais como as redes sociais. Nesses ambientes, a replicação (SHIFFMAN, 2014) de conteúdos de diversas naturezas (linguísticas, imagéticas, sonoras, multimodais, de eventos, links e afins) e, consequentemente, das posições ideológicas e dos significados sociais em funcionamento neles, constitui-se uma gama complexa de fatores imiscuídos na produção de uma posição situada de agência nos espaços em rede. Enfim, passemos as análises dos textos que seguem.

Figura 2 - Texto em favor da liberdade sexual pela fanpage do Não Me Kahlo ${ }^{13}$

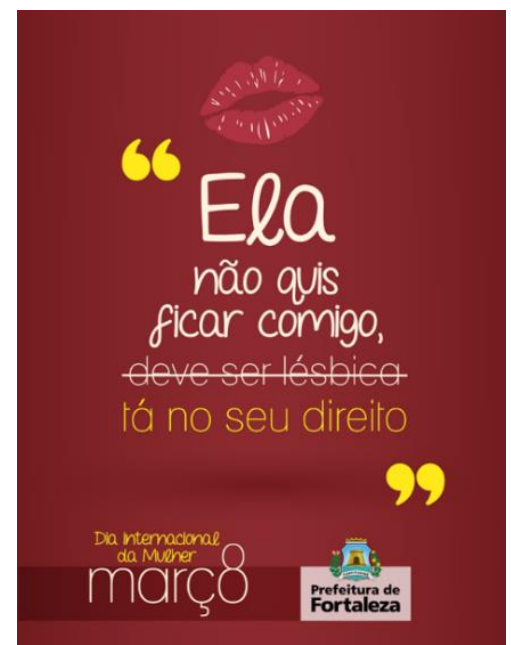

Fonte: Disponível em: <https://www.facebook.com/PrefeituradeFortaleza/photos/pcb.

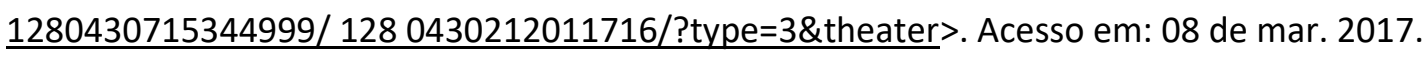

\footnotetext{
${ }^{12}$ Disponível em:

https://www.facebook.com/PrefeituradeFortaleza/photos/pcb.1280430715344999/1280429998678 404/?type=3\&theate. Postado em: 08 mar. 2017. Acesso em: 08 mar. 2017.
} 
$\mathrm{Na}$ figura 2, podemos perceber como elementos de natureza linguística e imagética aparecem imbricados na elaboração da superfície textual multimodal, produzindo sentidos que ultrapassam tal limiar. Pelo efeito imagético-discursivo da taxação ${ }^{14}$ de uma porção do texto linguístico emergem sentidos que apontam para o mote central que caracterizará a agência das posições enunciativas ${ }^{15}$ assumidas em ambos os textos em análise, na figura 2 e na figura 3: a manipulação de vozes sociais antagônicas, de um lado àquelas relativas ao machismo e de outro aquelas referentes ao feminismo. A partir desse modo de operação, a luta pela hegemonia na categorização em torno das mulheres, em especial, o modo como esta gere (ou deveria gerir) sua sexualidade, é posto em evidência, veiculando, de um lado, significados que ancoram numa visão machista e subalternizadora das mulheres, e de outro, possibilidades de significação que se inscrevem no ideário feminista de luta contrahegemônica, com vistas à emancipação do corpo e da experiência sexual feminina.

Como consequências do referido recurso à taxação, efetuada em parte do texto, não numa parte qualquer, como demonstraremos a seguir, podem ser identificadas duas possibilidades de leitura, sendo que uma delas aparece autorizada, por estar fora do tracejado, e outra aparece sob efeito de interdição (FOUCAULT, 2014), a saber: "Ela não quis ficar comigo, deve ser lésbica".

Deste enunciado, a priori, podemos destacar três expressões referenciais: ela, comigo e lésbica. Por meio da expressão referencial ela, pronome pessoal usual para a designação de elementos reconhecidos socialmente como designáveis ao gênero gramatical feminino, o objeto-de-discurso relativo à "mulher" é introduzido na figura 1. Tal inferência é deduzível contextualmente, inclusive conforme o recurso imagético que está anteposto a expressão linguística: uma marca de batom que poderia ser atribuída a um beijo "de uma mulher" impresso num papel, isto segundo os padrões heteronormativos ${ }^{16}$, socialmente aceitos, inclusive, para o uso de cosméticos.

No influxo de tais interpretações textualmente orientadas, a expressão referencial em análise aponta, ainda, para a condição de mulher "genuinamente feminina", a qual se realiza pelo atendimento desta à reprodução dos papeis sociais normatizados, no que tange ao exercício da sexualidade, calcados numa heterossexualidade compulsória e na disponibilidade tácita desta "presumida mulher heterossexual" submeter-se às investidas sexuais realizadas pelos homens. Nesse sentido, tal feminilidade condicional passa a ser gerida pelo poder do

\footnotetext{
${ }^{14}$ Efeito tipográfico no qual é traçado um risco sobre uma porção textual.

${ }^{15}$ Neste trabalho, em diálogo com as ideias de Bakhtin (1992) e Fairclough (2001), entendemos por posição enunciativa um determinado lugar social e ideológico, construído discursivamente, a partir do qual os sentidos são produzidos.

${ }^{16}$ Termo desenvolvido e cunhado em 1991 por Michael Warner que significa, grosso modo, aquilo que é tomado como parâmetro de normalidade em relação à sexualidade, para designar como norma e como normal a atração e/ou o comportamento sexual entre indivíduos de sexos diferentes. Em termos de sociedade eurocêntrica, o padrão heteronormativo diz respeito ao homem cisgênero e heterossexual (cf. PETRY; MEYER, 2011, p. 196).
} 
"macho". Assim, vemos como as relações de hegemonia na dominação das mulheres, de seu corpo e de sua sexualidade, o que configura em grande parte o núcleo central do patriarcado, modelo político-cultural das sociedades ocidentais, estão em funcionamento neste discurso. Desse modo, pensamos que:

\begin{abstract}
A dominação dos homens sobre as mulheres e o direito masculino ao acesso sexual a elas estão em questão na formulação do pacto original. O contrato social é uma história de liberdade; o contrato sexual, uma história de dominação. O contrato original cria ambas: a liberdade e a dominação. A liberdade do homem e a sujeição da mulher derivam do contrato original e o sentido de liberdade civil não pode ser compreendido sem a metade perdida da história que revela como o direito patriarcal dos homens sobre as mulheres é criado pelo contrato. A liberdade civil nação é universal - é um atributo masculino e depende do direto patriarcado. (...) O pacto original é tanto um contrato sexual quanto social: é social no sentido patriarcal - isto é, o contrato cria o direito político dos homens sobre as mulheres -, e também sexual, no sentido do estabelecimento sistemático dos homens aos corpos das mulheres. 0 contrato está longe de se opor ao patriarcado: ele é o meio pelo qual se constitui o patriarcado moderno. (PATEMAN, 1993, p. 16-17 apud SAFFIOTI, 2004, p. 56).
\end{abstract}

Dessa perspectiva, a partir do momento em que a este objeto-de-discurso "mulher" é atribuída uma agentividade (o modo como a agência é representada pelos processos verbais) que se opõe aos interesses da sociedade patriarcal, no que tange a gestão do corpo e da sexualidade feminina, materializada no texto pela construção argumental na qual a expressão referencial anteriormente analisada aparece engajada - [ela] "não quis ficar comigo, deve ser lésbica" - é acarretada no plano linguístico (pela renomeação), textual (pela recategorização) e discursivo (rediscursivização) ${ }^{17}$ uma transformação, a inserção da mulher, introduzida pela referência ela, numa nova categoria, ou seja, recategorizando-a com vistas a negar-lhe sua "genuinidade" feminina, nos termos citados.

Desse modo, quando esse mesmo referente (ela) é recategorizado como lésbica, atribui-se a essa expressão referencial a função de materializar, na/pela linguagem, uma visão pejorativa e marginalizadora segundo a ideologia heteronormativa de tal posição enunciativa machista, sendo essa posição marcada no texto pela expressão referencial comigo, destinada àqueles que não se enquadram nos padrões pré-determinados socialmente para uma sexualidade vista como normal/aceitável no interior de uma matriz sexual patriarcal, a heterossexualidade. Nesse sentido, a voz do outro, que fala de uma discursividade ligada ao ideário machista, coloca-se em posição de julgamento em relação à mulher, estabelecendo como parâmetro para isso o atendimento por parte dela às suas investidas sexuais, conferindo

\footnotetext{
${ }^{17}$ Uma vez que a discursivização diz respeito ao modo como determinados sujeitos sociais, situações factuais, eventos ou afins são discursivizados, ou seja, representados no discurso, tomamos a rediscursivização, em analogia terminológica as duas categorias citadas anteriormente, renomeação e recategorização, como um processo de mudança no modo como um desses elementos, no caso, o objeto-de-discurso "mulher", é discursivizado numa mesma situação de enunciação concreta, num mesmo texto.
} 
a si mesmo o poder de significá-la na linguagem, por meio da categorização/recategorização do objeto-de-discurso que a representa.

Do ponto de vista de tal perspectiva ideológica, se a mulher se recusa a atender às expectativas sociais para si no que tange à subserviência sexual ao homem, esta certamente não deve ser uma "mulher normal"/“mulher verdadeira". Apesar de não ser este o foco de nossas análises neste trabalho, reconhecemos que tal interpretação parece-nos ainda mais autorizada se observarmos a modalidade deôntica de obrigatoriedade (NEVES, 2000), da qual este verbo "dever" ("ela não quis ficar comigo, deve ser lésbica") é dotado, evocando, assim, sentidos semântico-pragmáticos, em transbordamento para o nível discursivo, nos quais o que é afirmado por tal posição enunciativa é avaliado como certo, verdadeiro e compulsoriamente destinado a acontecer.

Tendo em vista as discussões até aqui empreendidas, vemos como os sentidos atribuídos ao objeto-de-discurso mulher indicam sua categorização/recategorização na voz enunciativa veiculada pela expressão referencial dêitica comigo. Inicialmente, tal referente (mulher) é introduzido através de uma anáfora indireta ${ }^{18}(e / a)$, sendo recuperável quer pragmaticamente, pela alusão ao Dia Internacional da Mulher, quer pelo cotexto linguístico, graças às pistas (âncoras) presentes na superfície textual, como o gênero gramatical em que as demais expressões referenciais são empregadas, ou (ainda, imageticamente, por meio da figura que alude a uma marca de batom deixada por um beijo. Posteriormente, na figura 2 , tal referente é recategorizado anaforicamente pela expressão lésbica, a qual realiza sua ancoragem em contextos que remontam à história social das mulheres no Ocidente, construída sob o signo da dominação masculina, e, segundo a qual, o corpo e a sexualidade femininos são objetos constantemente à disposição do homem, daí a avaliação de tal significado social em nível deôntico, como expresso pela forma verbal dever empregada no texto (deve ser lésbica).

Seguindo o caminho de progressão textual no qual o texto em análise é concebido, levando-se em conta a taxação, numa segunda leitura, teríamos:

"Ela não quis ficar comigo, deve ser lésbica tá no seu direito"

Como numa postura de recusa aos modos de significação do objeto-de-discurso "mulher" até então produzidos na progressão do texto, fica marcada, no funcionamento dos processos de referenciação em análise, uma agência que opera a interdição dos sentidos produzidos pelos mecanismos de referenciação que processam a composição textualdiscursiva até agora discutida ("ela não quis ficar comigo, deve ser lésbica"). Exercendo tal função, o recurso à taxação de certa porção textual, bem como o acréscimo de uma parte nova à sequenciação do texto, marcada inclusive pela diferença de cores em que ambas as

\footnotetext{
18 "Essa estratégia [referencial], em que um novo referente é apresentado como já conhecido, em virtude de ser inferível por conta do processamento sociocognitivo do texto, é chamada de 'anáfora indireta'. As anáforas indiretas evidenciam essencialmente três aspectos: a não vinculação da anáfora com a correferencialidade; a introdução de referente novo e o status de referente novo expresso no cotexto como conhecido" (CAVALCANTE, 2012, p. 125-126).
} 
partes aparecem materializadas (branco numa parte e amarelo noutra), produzem novos processos de discursivização do "objeto" em questão, reconfigurado no texto, tanto em sua dimensão linguística (porção de texto) quanto imagética (o traço sobre o texto deixado pela taxação enquanto marca não linguística), por isso multimodal.

Em relação de imbricação com tais reconfigurações no plano material do texto analisado, reconfigurações na dimensão sociodiscursiva também podem ser evidenciadas, uma vez que inscrevem na textualidade novas perspectivas ideológicas as quais agenciam novos sentidos para as mulheres, a partir de uma nova posição enunciativa não apenas diversa daquela em funcionamento até a marcação da interdição discursiva operada pela taxação, mas também oposta à voz social até então audível na construção da textualidade: a posição enunciativa feminista. Subjacente a tais estratégias, vemos materializada, em termos textuaisdiscursivos, o modo como a luta pela desnaturalização e deslegitimação de significados sociais ligados à cultura machista na compreensão da sexualidade feminina manipula tal discurso, em função da luta contra-hegemônica, a fim de autorizar novos sentidos, os quais discursivizam as mulheres a partir de categorias as quais visam emancipar seus corpos e suas identidades.

Diante disso, podemos constatar como a heterogeneidade enunciativa própria de uma noção dialógica de linguagem, pensada por Bakhtin (1992) e incorporada na perspectiva do discurso desenvolvida por Fairclough (2003) - a qual consiste, em linhas gerais, na ideia de que todo discurso é construído a partir do discurso do outro, que é o "já dito" sobre o qual qualquer discurso se constrói - , aparece presentificada nos processos textuais-discursivos aqui discutidos. Na figura 2, podemos ver a evocação da voz do "outro", o qual enuncia partir de uma prática social na qual a mulher é significada como "objeto sexual a serviço do homem", a fim de confrontá-la, por meio da interdição imagético-discursiva de seu dizer, de seu discurso.

Nesse jogo que retoma o "já dito" sobre a mulher para interditá-lo, para invalidar sua possibilidade de significação pela marca imagética do traço sobre o texto, que na prática da escrita em ambientes não digitais indica a invalidação do que subscrito ao tracejado, emergem indícios da luta hegemônica pela discursivização das mulheres, uma vez que, em perspectiva crítica, conforme indicam Chouliaraki \& Fairclough (1999, p. 62), hibridismos discursivos não devem ser vistos apenas como uma questão textual, uma vez que podem constituir também "estratégias de luta hegemônica".

Desse modo, a nova leitura, posterior a referida intervenção no discurso do outro evocado na enunciação, no discurso machista (Ela não quis ficar comigo, deve sésbica tá no seu direito), aponta para sentidos nos quais o objeto-de-discurso "mulher" é recategorizado, do ponto de vista do processamento textual, a partir da ressignificação da expressão referencial ela. Se antes tal termo era recuperado pela categoria lésbica, a qual no interior da discursividade machista é dotada de valor pejorativo por negar a heterossexualidade compulsória, como já discutido, agora tal referente não mencionado, (as mulheres), é reconstruído a partir de uma voz social a qual afirma o direito da mulher sobre seu corpo e sua sexualidade, uma vez que esta, dessa posição enunciativa feminista, não está 
mais submissa ao atendimento de padrões de subserviência afetivo-sexual ao homem como índice de afirmação de luta legitimada e de seu reconhecimento como mulher.

Nesse percurso analítico, compreendemos como a manipulação de uma voz social hegemônica sobre a mulher pode funcionar como um exercício de contrapoder (MELO, 2012, p. 70) com vistas à produção de significados sociodiscursivos contra-hegemônicos e emancipatórios que visem emancipar as mulheres, a partir de seu empoderamento social ${ }^{19}$ (VASCONCELOS, 2003). Assim, podemos perceber, mediante seus múltiplos processos textuais-discursivos de constituição, "a importância do texto como meio, local, registro de interacções sociais, contestações, resoluções (mais ou menos temporárias) e o efeito destas na linguagem" (KRESS, 1997, p. 55), sobretudo no que tange ao estabelecimento de práticas sociais e discursivas que visem à superação de relações de opressão e discriminação baseadas em classe, raça, etnia, gênero e orientação sexual, às quais estão na base de modelos sociais construídos sob a égide de desigualdades estruturais e estruturantes.

Avançando na compreensão do funcionamento dos processos textuais-discursivos em análise, com vistas a perceber indícios textuais de mudanças sociais e discursivas no modo de representar as mulheres no discurso online, passemos a análise do texto que segue.

Figura 3 - Texto com discurso em favor da liberdade de autodeterminação de gênero replicado pela Não Me Kahlo

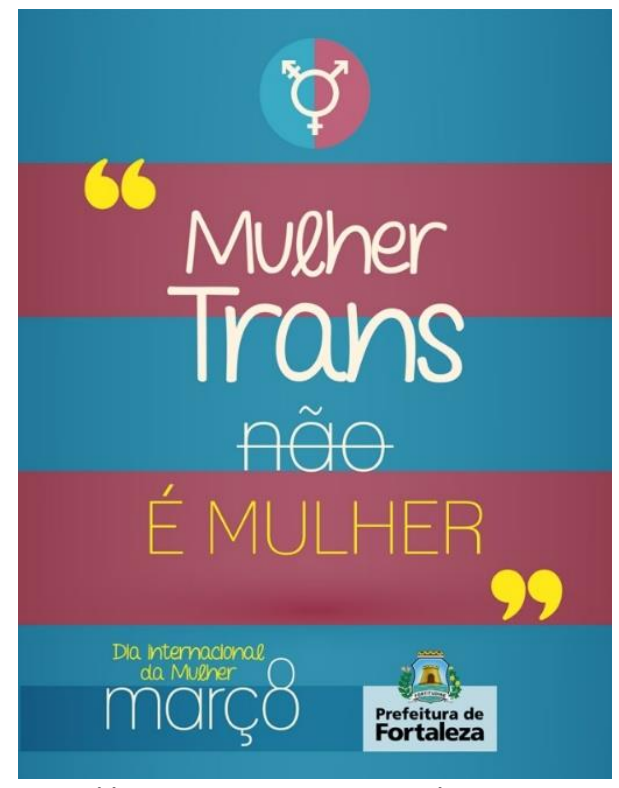

Fonte: Disponível em: < https://www.facebook.com/PrefeituradeFortaleza/photos/pcb.12 80430715344999/12804 303353 45037/?type=3\&theater . Acesso em: 08 de mar. 201

\footnotetext{
${ }^{19}$ Empoderamento "diz respeito às possibilidades de que a ação local fomente a formação de alianças políticas capazes de ampliar o debate da opressão no sentido de contextualizá-la e favorecer a sua compreensão como fenômeno histórico, estrutural e político" (VASCONCELOS, 2003). Nesse sentido, pode ser entendido como "um processo de mobilizações e práticas que objetivam promover e impulsionar grupos e comunidades na melhoria de suas condições de vida, aumentando sua autonomia" (KELBA; WENDALSEN, 2009, p. 736).
} 
Na figura 3, vemos que a estratégia de evocação da voz social machista com vistas à sua interdição imagético-discursiva, enquanto estratégia textualmente realizada pela recategorização do objeto de discurso "mulher", é novamente empregada, mas dessa vez para denunciar uma nova faceta de tal posição: a transfobia. Entendida como relativa àquelas "reações de ódio e rejeição perpetradas física, institucional, simbólica e linguisticamente contra a pessoa transexual" (SILVA, 2017, p. 75), estas são motivadas pelo não reconhecimento de seus corpos e identidades, uma vez que eles são tomados como ininteligíveis por estarem em conflito com as normas de gênero socialmente estabelecidas. Dessa visada, os "gêneros 'inteligíveis' são aqueles que, em certo sentido, instituem e mantêm relações de coerência e continuidade entre sexo, gênero, prática sexual e desejo" (BUTLER, 2017, p. 43).

Entendendo que "a viabilidade de nossa identidade depende dessas normas sociais" (BUTLER, 2017, p. 7) e que, especificamente, esta depende de nosso atendimento a tais normas, podemos entrever como a partir de uma visão hegemônica do gênero e da sexualidade, as mulheres trans são categorizadas como inviáveis (não-mulheres), como transgressoras das condições impostas para seu reconhecimento como mulheres, tonandose, assim, dotadas de corpos e identidades abjetas, não-humanas, por isso, deploráveis, violentáveis, inclusive, pela violência do não reconhecimento identitário. Tal visão aparece marcada pelo efeito de sentido gerado pela negação inscrita na porção de texto sobreposta à taxação: "Mulher trans não é MULHER".

Nesse contexto, além dos processos de predicação do sujeito em funcionamento na parte linguística do texto multimodal em análise ("Mulher trans não é MULHER" / "Mulher trans ó é mulher"), quando se leva em conta o efeito da taxação, ou seja, da intervenção da posição enunciativa feminista sobre o discurso transfóbico, dá-se também, no plano textualdiscursivo, um processo de recategorização do objeto-de-discurso "Mulher trans", reelaborando, assim, o modo como este é construído discursivamente.

Dessa ótica, a interdição de tal significação, realizada nos mesmos termos do que ocorre na figura 2, indica uma ação política na linguagem que demarca a obliteração e a deslegitimação de sentidos transfóbicos sobre as mulheres, os quais aparecem ligados a uma visão determinística da biologia e essencialista da identidade de gênero. Tais processos de legitimação e deslegitimação de discurso sobre as mulheres evidenciam a luta hegemônica em funcionamento, como contexto que modela e motiva os processos de categorização e recategorização multimodais em funcionamento no texto ativista analisado, no qual tais processos são geridos de forma eminentemente política.

Nesse ponto, os recursos imagéticos empregados na textualização aparecem novamente imbricados na produção de sentidos para as mulheres, como parte elemento que participa do processo de recategorização do objeto de discurso "mulher trans". É possível notar uma oposição entre letras grafadas em minúsculas e maiúsculas na inscrição da palavra "mulher" no texto, a qual parece-nos bastante significativa, sobretudo em face da oposição pré-estabelecida pela disposição textual entre aqueles sujeitos que seriam categorizados 
como "Mulheres trans", menos mulheres, mulheres em minúsculo, e aqueles que seriam, de fato, "MULHERES", cujas identidades e corpos seriam socialmente inteligíveis. Em contrapartida, pelo efeito das fontes e cores escolhidas, a inscrição "Mulher trans", especialmente "trans", ganha maior destaque na superfície textual, maior visibilidade, em consequência da interdição já referida.

Nessa direção, ao interditar o discurso de uma posição enunciativa transfóbica, a partir da interdição de certos processos de categorização, os quais produzem sociodiscursivamente mulheres trans como inviáveis, ininteligíveis, não-mulheres, negando-lhes, assim, sua identidade social, a posição enunciativa feminista construída pela fanpage Não Me Khalo põe em circulação um discurso que coloca em suspenso o significado da categoria "mulher", ao desestabilizar a pretensa homogeneidade ou estabilidade de sua categoria.

Se, na voz social produzida por um discurso transfóbico, uma mulher trans (contraditoriamente, uma não-mulher) não pode ser reconhecida como uma "MULHER" (mulher "verdadeira"/socialmente viável, em maiúsculo), ou seja, não pode ser compreendida por tal categoria linguístico-discursiva e de gênero, pelas razões já discutidas, a intervenção realizada pela posição que age no discurso da fanpage, mediante a taxação do elemento que

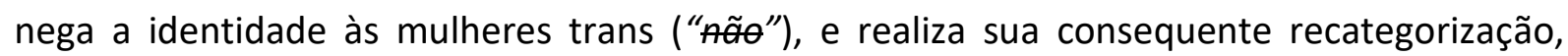
legitima tal identidade pelo alargamento/ressignificação da referida categoria.

Ainda nos atendo à natureza multimodal do texto em análise, podemos ver que as cores que formam o plano de fundo da imagem (azul e rosa), em jogo com a cor das letras nas quais a expressão "Mulher trans" é escrita (branca), fazem alusão à bandeira internacional do orgulho trans, na qual:

as listras na parte superior e inferior são azul-claro, a cor tradicional dos garotos. As listras ao lado são cor-de-rosa, a cor tradicional das garotas. A faixa central é branca, para aqueles que estão entre os dois sexos, em transição de um para o outro ou consideram ter um gênero neutro ou indefinido. O padrão é tal que não importa o caminho que você siga, ele é sempre correto, o que significa que encontramos o caminho de nossas vidas (TRANSPROJETO, 2017, s/p.).

Ainda seguindo esse percurso interpretativo, é interessante notar que a referida expressão ("Mulher trans"), além de estar representada em branco, cor que indicaria a instabilidade das duas outras categorias de gênero quando pensadas hegemonicamente - de modo binário, estanque e excludente (homem $X$ mulher) - é disposta de modo que sua extensão "ocupa", simultaneamente, ambas as áreas designadas aos gêneros como tradicionalmente pensados, aquelas demarcadas em azul e rosa. Corroborando tais sentidos, aparece disposto na parte superior do texto um símbolo comumente referido como destinado a representar a transexualidade, o qual "combina símbolos referentes aos organismos masculinos e femininos para identificar travestis, transexuais e outras pessoas transgênero" (JESUS, 2012, p. 20). Graças a esses modos de agência na composição multimodal do texto em 
análise, ficam marcadas as intersecções entre semioses linguísticas e imagéticas na produção dos processos de categorização e recategorização das mulheres, os quais se realizam sob influência das disputas políticas acerca das questões de gênero, evidenciando o caráter discursivo dos processos de referenciação.

Assim, vemos como a produção de sentidos emancipatórios para as mulheres no discurso feminista online no contexto do ativismo digital na figura 3, aqui evidenciados pela liberdade de autodeterminação de gênero implícita na legitimação de identidades trans, parte de uma concepção de gênero que se aparta de uma visão binária, excludente ou determinada pela biologia, funcionando, assim, como uma forma de contra-poder que, por meio de mudanças discursivas (FAIRCLOUGH, 2003), tais como aquelas operadas através dos efeitos discursivos de processos de referenciação, visa a produzir mudanças sociais (FAIRCLOUGH, 2003) significativas, no que tange à superação das desigualdades e outras violências baseadas em gênero.

\section{Considerações finais}

Ao cabo do percurso de reflexão aqui empreendido, podemos constatar como uma postura integracionista, no que diz respeito à proposição de um diálogo entre teorias que se debruçam sobre os processos de textualidade (como a Linguística Textual contemporânea) e perspectivas que focalizam, numa visada crítica e interdisciplinar, o nível discursivo das práticas de linguagem (como a Análise Crítica do Discurso), pode se mostrar útil para o alargamento da compreensão do modo como os sentidos são produzidos nos textos e circulam nos domínios do ciberespaço.

Dessa visada, sustentamos que os processos de referenciação, observados através de um prisma sociocognitivo-interacional e discursivo, como demonstrado nas análises aqui empreendidas, participam da elaboração da realidade social das mulheres, seja no sentido de atualizar significados ligados ao ideário machista do patriarcado, no qual a mulher é subalternizada, seja no percurso de construir novas significações emancipatórias para tais sujeitos, evidenciando, assim, o uso da linguagem efetivamente como ato político implicado na luta hegemônica com vistas à mudança social e à superação de situações de violência e desigualdade.

Como uma ação pública que se realiza por meio de negociações/disputas intersubjetivas e de diferentes ordens hegemônicas no âmbito das relações sociais, os significados atribuídos aos sujeitos são constituídos pelo partilhamento, refutação, modificação, reconstrução de diferentes sistemas de conhecimento e crença. É graças a essa dinâmica que o ciberespaço e os discursos que nele circulam, dadas as suas múltiplas possibilidades de conexão e de compartilhamento, torna-se um campo fértil para investigações em torno dos significados sociais multissemióticos produzidos para diferentes 
grupos sociais, dentre eles as mulheres, especialmente em contextos de engajamento e militância social, como é o caso do ativismo digital feminista.

Por fim, parece-nos cada vez mais pertinente apostar numa Linguística em movimento que, à revelia da sua multiplicidade de objetos, em suas diferentes orientações, se reconheça interdisciplinar e sempre aberta a novas teorizações, quer seja mediante novos desenvolvimento de discussões já consagradas no campo, quer seja rumando a novas proposições híbridas, concebidas no diálogo com outras áreas dos estudos da linguagem e/ou com outros campos do saber, encarando o desafio de empreender uma prática teórica e analítica satisfatória na compreensão do objeto de estudo "texto", em face de sua crescente complexidade.

\section{Referências}

BAKHTIN, M. Os gêneros do discurso (1952-1953). In: BAKHTIN, M. Estética da criação verbal. Trad. Maria Ermantina Galvão Gomes e Pereira. São Paulo: Martins Fontes, 1992. p. 277-326.

BRAGA, D. B. A comunicação em rede e os impactos nas possibilidades de participação social: reflexões introdutórias. In: BRAGA, D. B. (org.) Tecnologias Digitais da Informação e da Comunicação Digitais e Participação Social. São Paulo: Cortez, 2016. p. 13-30.

BUTLER, J. Lenguaje, poder e identidad. Madrid: Síntesis, 1997.

BUTLER, J. Problemas de gênero: feminismo e subversão da identidade. Tradução de Renato Aguiar. Rio de Janeiro: Civilização Brasileira, 2017.

CAVALCANTE, M. M. Os sentidos do texto. São Paulo: Contexto, 2012.

CAVALCANTE, M. M.; CUSTÓDIO FILHO, V.; BRITO, M. A. P. Coerência, referenciação e ensino. 1. ed. São Paulo: Cortez, 2014.

CHOULIARAKI, L. FAIRCLOUGH, N. Discourse in late modernity: rethinking critical discourse analysis. Edinburgh: Edinburgh University Press, 1999.

CIULLA. A. Categorização e referência: uma abordagem discursiva. Cadernos de Estudos Linguísticos, v. 56, n. 2, p. 247-258, 2014. https://doi.org/10.20396/cel.v56i2.8641477

COELHO, P. M. F.; COSTA, M. R. M. O ativismo digital: reflexões e apontamentos semióticos. TECCOGS. n. 8. 2013.

CUSTÓDIO FILHO, V. Aspectos multimodais envolvidos na construção da referência. In: Congresso Internacional da Abralin, VI, 2009, João Pessoa. Anais do VI Congresso Internacional da Abralin. João Pessoa: Ideia, 2009. p. 2927-2936.

CUSTÓDIO FILHO, V. SILVA, O. F. O caráter não linear da recategorização referencial. In: CAVALCANTE, M. M. LIMA, S. M. C. (org.) Referenciação: teoria e prática. São Paulo: Cortez, 2013. p. 59-87.

DELPHINO, F. B. Uma leitura multimodal de um texto publicitário. Sinergia, v. 2, n. 1, 2001.

FAIRCLOUGH, N. Discurso e mudança social. Brasília: Universidade de Brasília, 2001. 
FAIRCLOUGH, N. Discurso e mudança social. Brasília: Editora UnB, 2003.

FAIRCLOUGH, N. Discurso, mudança e hegemonia. In: PEDRO, E. R. (org.) Análise Crítica do Discurso: uma perspectiva sociopolítica e functional. Lisboa: Caminho, 1997, 77-104.

FOUCAULT, M. A ordem do discurso. São Paulo: Edições Loyola, 2014.

GIDDENS, A. As consequências da modernidade. São Paulo: Unesp, 1991.

GIDDENS, A. Modernidade e identidade. Rio de Janeiro: Zahar, 2002.

GODOI, C. Celular: representações da desigualdade na mobilidade. 2009. 127f. Dissertação (Mestrado em Ciências da Comunicação) Escola de Comunicações e Artes da Universidade de São Paulo, São Paulo, 2009.

GRAMISCI, A. Cadernos do cárcere - Maquiavel. Notas sobre o Estado e a política, vol. 3, Rio de Janeiro: Civilização Brasileira, 2002.

HARAWAY, D. Manifesto ciborgue. Ciência, tecnologia e feminismo-socialista no final do século XX. In: HARAWAY, D.; KUNZRU, H.; TADEU, T. (org.) Antropologia do ciborgue: as vertigens do pós-humano. Belo Horizonte: Autêntica, 2009, p. 33-118.

JESUS, J. G. Orientações sobre identidade de gênero: conceitos e termos. Brasília: Biblioteca Nacional, 2012.

KELBA, M. E. WENDAUSEN, A. Empoderamento: processo de fortalecimento dos sujeitos nos espaços de participação social e democratização política. Saúde e Sociedade, vol.18, n.4, São Paulo, out./dez., p. 733-743, 2009. https://doi.org/10.1590/S0104-12902009000400016

KOCH, I. G. V. Desvendando os segredos do texto. 2. Ed. São Paulo: Cortez, 2003.

KOCH, I. G. V. Introdução à linguística textual. São Paulo: Martins Fontes, 2004.

KOCH, I. G. V. Referenciação e orientação argumentativa. In: BENTES, A, C.; KOCH, I. G. V.; MORATO, E. M. (Org.). Referenciação e discurso. São Paulo: Cortez, 2005. p. 33-52.

KRESS, G. Before writing: rethinking the paths to literacy. London: Routledge, 1997.

LEMOS, M. G. Ciberfeminismo: novos discursos do feminino em redes eletrônicas. 2009. 129 f. Dissertação (Mestrado) - Curso de Comunicação e Semiótica, Pontifícia Universidade Católica de São Paulo, São Paulo, 2009.

LÉVY, P. Cibercultura. Trad. Carlos Irineu da Costa. São Paulo: Editora 34, 1999.

LIMA, G. O. S. O rei do cangaço, o governador do sertão, o bandido do sertão, o cangaceiro malvado: processos referenciais na construção da memória discursiva sobre lampião. Campinas, 2007, 340f. Tese (Doutorado) - Instituto de Estudos da Linguagem, Universidade Estadual de Campinas, 2008.

LOPES, L. P. M. Os novos letramentos digitais como lugares de construção de ativismo político sobre sexualidade e gênero. Trab. linguist. apl. [online], v. 49, n. 2, p. 393-417, 2010. https://doi.org/10.1590/S0103-18132010000200006

MELO, I. F. Por uma análise crítica do discurso. In: MELO, I. F. (org.) Introdução aos estudos críticos do discurso. Campinas: Pontes, 2012, p. 53-98.

MONDADA, L. DUBOIS, D. Construção de objetos de discurso e categorização: uma abordagem dos processos de referenciação. In: CAVALCANTE, M. M.; RODEIGUES, B.; CIULLA, A. (org.) Referenciação. São Paulo: Contexto, 2003, p. 17-52. 
MORAES, D. Comunicação, hegemonia e contra-hegemonia: a contribuição teórica de Gramsci. Revista Debates, Rio Grande do Sul, v. 4, n. 1, p. 54-77, 2010.

\section{https://doi.org/10.22456/1982-5269.12420}

MORAES, D. Comunicación virtual, activismo político y ciudadanía. In: CONGRESO INTERNACIONAL COMUNICACIÓN Y REALIDAD, 3., Barcelona. Actas del III Congreso Internacional Comunicación y Realidad. Barcelona: Universidad Ramon Llull, 2005. p. 67-76.

MORAES, D. O ativismo digital. Biblioteca On-line de Ciências da Comunicação, Lisboa, p. 1$15,2001$.

NÃO ME KAHLO. Quem somos nós. 2017. Disponível em: http://www.naomekahlo.com/sobre. Acesso em: 20 ago. 2017.

NEVES, M. H. M. Gramática de usos do português. São Paulo: UNESP, 2000.

SILVA, D. C. P. Atos de fala transfóbicos no ciberespaço: uma análise pragmática da violência linguística. 2017. 200f. Dissertação (Mestrado em Letras) - Programa de Pós-Graduação em Letras, Universidade Federal de Sergipe, São Cristóvão, 2017.

RESENDE, V. Análise de Discurso Crítica como interdisciplinar para a crítica social: uma introdução. In: MELO, I. F. (org.) Introdução aos estudos críticos do discurso. Campinas: Pontes, 2012, p. 99-112.

RESENDE, V. Análise discursiva crítica do uso de metáforas em uma interação etnográfica no Movimento Nacional de Meninos e Meninas de Rua. Revista da ABRALIN, v.8, n.1, p. 125-148, jan./jun. 2009. https://doi.org/10.5380/rabl.v8i1.52438

RESENDE, V. RAMALHO, V. Análise de Discurso Crítica. São Paulo: Contexto, 2016.

ROJO, R. H.; BARBOSA, J. Hipermodernidade, multiletramentos e gêneros discursivos. 1a.. ed. São Paulo: Parábola Editorial, 2015.

SAFFIOTI, H. I. B. Gênero, patriarcado, violência. 1. ed. São Paulo: Fundação Perseu Abramo, 2004.

SHIFMAN, L. Memes in digital culture. MIT Press, 2014.

https://doi.org/10.7551/mitpress/9429.001.0001

TRANSPROJETO. História da bandeira do orgulho trans. 2017. Disponível em: <https://transprojeto.wordpress.com/2014/04/03/historia-da-bandeira-do-orgulho-trans/>. Acesso em: 16 de set. de 2017.

VASCONCELOS, E. O poder que brota da dor e da opressão: empowerment, sua história, teorias e estratégias. Rio de Janeiro: Paulus, 2004.

Recebido em: 04/09/2018

Aceito em: 18/11/2018 